\title{
Video methodologies and engaging with
}

\section{mobilities}

\section{Richard Scriven}

PhD Candidate, Department of Geography, University College Cork, Ireland

The use of video in geographic research is becoming increasingly common, particularly in the study of bodies, practices and mobilities. It is being employed as one of a number of research methods to access and engage with movements as they are occurring in place. This article reviews the literature surrounding methodological developments and discussions of the role of video. A short video clip of people climbing Croagh Patrick, Co. Mayo Ireland, on a main pilgrimage day, is explored and interpreted as an example of a way in which video can be used in this type of research. The movements and moments in the recording will be analysed and related to themes with in the geographies of mobilities.

Key Words: Video, Methodology, Mobilities, Movement, Pilgrimage

\section{Introduction}

The study of mobilities, bodies and events-in-motion within social and cultural geography has presented both theoretical and methodological challenges. The resultant broadening of methodological approaches has included discussions on the use of video in research (Laurier and Philo 2006; Luff and Heath 2012; Morton 2005; Simpson 2011). Video is being appreciated as a research tool, a digital record, an analytical facility and a means of (re)presenting places and events. This interest has been facilitated by the availability of recording devices, userfriendly software and online-platforms (Crang and Cook 2007; Luff and Heath 2012).

This paper, like others (Garrett 2011; Simpson 2011; Spinney 2011), aims to contribute to the discussions concerning the incorporation of video into geographic research. It is particularly concerned with video as a fieldwork method that is employed as a means of accessing practices as they occur in place, with the material produced later being analysed and presented to an audience. A review of the literature concerning the conceptual and methodological debates within human geography around mobilities locates the role of video in a wider setting. A number of specific pieces concerning the use and experimentation with video, then, provide a summary of the current understandings of the method. A short video clip recorded as part of my fieldwork serves as an example of how video can be used to gain insight into bodily movements and mobilities. Specific corporeal movements and instances in the footage are discussed. The paper concludes with some observations of the use of video in geographical research.

\section{Mobilities, Methods and Video}

\subsection{Engaging with Mobilities}

Mobility is a significant area of study in the social sciences, with numerous commentaries on the emergence of the 'new mobilities paradigm' or a 'mobility turn' (Hannam et al. 2006; Sheller and Urry 2006). Geographers are engaging with a more mobile world by exploring how mobilities (and immobilities) are a central element in the interactions of people and place. Mobility is fundamental to the way we interact with the others and the world around us and as a geographical concept can be adopted as a means of engaging with and understanding the world analytically (Adey 2006; Cresswell 2006a; 2010; Jensen 2009). By considering the importance of movement, and the ways in which it is invested with meaning and how it is experienced, geographers can gain new insights into the 
spatial (Cresswell 2006a; 2010). This requires concepts and methods that can engage with the actuality and experiences of movement.

In methodological terms, new approaches have been adopted to study mobilities. The perceived gap between theoretical developments and research methods (Cresswell 2006b; D'Andrea et al. 2011; Lorimer 2010; Latham 2003) has resulted in attempts to broaden methodological horizons by modifying and experimenting with traditional qualitative methods (Davies and Dwyer 2007; Lorimer 2009). These approaches aim to access, capture and get closer to the events and practices of people in place and in real time. Jensen (2010) examines bodily movements and nonverbal momentary interactions in an urban public-square, while Morton's (2005, p.661) 'performance ethnography' aims to capture a sense of the 'now' and the unique spaces created during a traditional music session. Within these larger developments in mobile methodologies, video is advanced as one of the research techniques offering significant potential.

\subsection{Video}

\subsubsection{General}

The use of video has been the topic of numerous commentaries that can inform usage of the medium. While it has been argued that there has not been a full realisation of the potential of video as a research methodology (Garrett 2011; Luff and Heath 2012), its different applications have been highlighted, including the vivid presentation of scenes that would be difficult to convey in text (Crang and Cook 2007), the ability to evoke events and places (Morton 2005), and the production of permanent revisable documentation (Rosenstein 2002). It is these attributes of the medium that make it such a rich research tool.

Video is an observational based method. By capturing events and activities, the medium enables the exploration of how people use their bodies and spaces, and how people interact with spaces (Spinney 2009). This feature is fundamental to the employment of video as a tool that can assist in the study of mobilities. It opens up new opportunities to record and portray everyday practices and brief social interactions (Laurier and Philo 2006; Simpson 2011), as well as "gesture, movement, rhythm and flow" (Garrett 2011, p. 536) and the "sparkle and character" of an event (Rosenstein 2002, p. 24). Worlds of activity, motion and kinetics are made accessible to observation, analysis and re-presentation. Furthermore, video enables the recording of sound alongside moving images. This feature allows for the appreciation of soundscapes and the aural qualities of places, while also partially addressing biases towards the visual (Saldanha 2009).

The observational nature of video is complemented by other methods which can provide further detail especially regarding the experiential sphere. In this way, video is part of a suite of methods that are mutually reinforcing; for example, video can provide detailed documentation of interviews and field-notes can facilitate greater analysis of recorded footage (Crang and Cook 2007; Simpson 2011). This would also address warnings over the excessive use or dependency on technology in fieldwork which can distance the researcher from the immediate experiences of the practices being studied (Vergunst 2011).

\subsubsection{Drawbacks}

While there are distinct benefits to the use of video, there are number of issues associated with it. In practical terms, these include technical limitations, difficulty over distribution and control, and reluctance in the academy and publishing to utilise it (Garrett 2011). The filming process has its limitations, such as selectivity in the positioning of the camera (Rosenstein 2002) and the fact that important moments maybe lost as people or objects move out of frame (Luff and Heath 2012). While there is little the researcher can do in response to some of these issues, an awareness can ensure actions such as promoting the use of video and employing it carefully and responsibly.

As a heavily visual approach it is subject to the numerous criticisms, such as the inherent power dynamics, objectification and the privileging of the optical (Crang 2003; Rose 2012). Also, the ethics of recording people without their expressed permission, with implications for informed consent and anonymity, also raises concerns for the use of video. While there is debate on these issues, few commentators address them directly and even fewer 
provide clear guidance (Luff and Heath 2012; Rose 2012). In both cases, these primary drawbacks can be partially allayed by conducting research in a transparent and open manner, and by paying due regard to the appropriateness of circumstances and the rights, privacy, dignity and wellbeing of individuals.

\subsubsection{The Researcher}

The making of video recording implies the presence of researcher: the unseen operator of the recording device. The acknowledgment of this can be seen in a wider exploration of the corporeal presence of the researcher in the field (Crang 2003; 2005; Davies and Dwyer 2007; Longhurst 2009a). Appreciations of this highlight the significance of the implicit features, such as physical position of the researcher and the movements of the camcorder/camera, and the role they may play in influencing the behaviour of people and the analytical process. The consideration of such metadata leads to more reflective and insightful engagements and interpretations (Crang and Cook 2007; Garrett 2011)

\subsubsection{Analysis}

In the provision of a document that can be viewed in different ways and returned to time and time again, video is a medium ideally suited to detailed analysis. These facilities are especially useful in terms of the focus on bodily movements and unfolding events in this study. However, the analytical process of video materials, as is frequently the case, has been largely overlooked in commentaries (Luff and Heath 2012). In the context of the research process increasingly being discussed as a continual interpretative process (Delyser 2010; MacKian 2010), it is important to understand that the making of the recording, the editing stage and the selection of material for detailed scrutiny are all judgemental acts involving different degrees of consideration (Luff and Heath 2012).

Interpretation that centres on the examination of movements and mobilities, relies detailed viewing and reviewing of the material. This repeated re-viewing serves as a type of witnessing the events anew, creating new understandings and experiences. Indeed, Rosenstein (2002) refers to this as a dynamic process that assists in the production of 'thick description', as outlined by Geertz (1973), which can disentangle the complex cultural and conceptual structures of the subject-matter. Recordings can be slowed-down and freeze-framed, facilitating greater analysis of fleeting moments and movements that can be 'stretched out' and studied in detail (Spinney 2011). Although approaches and tools exist for analysing recordings (Crang and Cook 2007), the sheer volume and complexity of data in video makes analysis centred on categorisations difficult (Luff and Heath 2012). Despite the ability of the medium to record and frame events, it is still the researcher who interprets the content and gives it meaning (Spinney 2011). Moreover, video generally has the added feature (although not in all cases) that the recorded material can be presented to wider audiences, which facilitates transparency and accessibility.

\section{Approaching Pilgrimage}

Pilgrimage is one of the oldest and most prominent religious and cultural phenomena in the world (Collins-Kreiner 2010). Millions of people annually, within most faiths and cultures, participate in some form of pilgrimage. As a distinctly spatial activity, pilgrimage is of particular interest to geographers (Nolan 1983; Sopher 1967). It involves the movement of people to and through specific places because of personal and communal beliefs or motivations, in ways that shape and create cultural landscapes and involve the circulation of objects, ideas and capital. Irish pilgrimage traditions are seen as having a continuing role in contemporary society (Foley 2011), with many ancient practices existing in different forms in sites that frequently had pre-Christian relevance (Nolan 1983; Nolan and Nolan 1997).

Pilgrimage, as activity that centres on movement and its meanings, can be studied as an embodied mobility. Through the performance of pilgrimage, the people involved shape themselves and landscape around them. For example, the people who climb Croagh Patrick, Ireland's 'holy mountain', are engaging in an active embodied process. While undertaking this challenging walk some complete different ritual movements along the way. Frequently, in the ritualised setting of a pilgrimage the corporeal movements and passing moments of the journey are highly relevant. 
In order to gain an understanding of this phenomenon, video is being employed as part of a methodology that researches these practices as they happen in place.

\section{Encountering Mobilities}

In order to fully appreciate the role of video, a short clip is embedded in this article. Its inclusion enables a demonstration of the potential of video as a research tool for engaging with corporeal mobilities and allows for comment on the use of the medium and the analytical processes involved. The recording is considered in terms of an initial brief description of the content, - the physical landscape, the general movement of people and any other key features - which is then followed by observations on specific movements and moments. This opening series of 'shallow' engagements will produce insights that then can be used for deeper analysis.

\subsection{Setting}

The video recording is a twenty-eight second film of people climbing and descending Croagh Patrick on 29 July 2012. The film was recorded at 7.12am from several hundred metres up a section of the main trail called Casán Phádraig (the path of St Patrick) facing eastwards. I was holding the digital camcorder while sitting on an outcrop of bedrock.

Croagh Patrick $(764 \mathrm{~m})$ is associated with St Patrick and is one of the main pilgrimage sites in Ireland, as well as being of considerable cultural and touristic significance. While it attracts visitors throughout the year, the main day of pilgrimage is Reek Sunday, the last Sunday in July, when thousands ascend and Catholic services are held on the summit. The pilgrimage on 'the Reek', as it is locally known, involves the climb and 'rounding' rituals (walking around or kneeling at certain features and repeating specific prayers) (Hackett 2003). There is also a tradition of pilgrims climbing barefoot. This day is seen as a remarkable phenomenon and one of the few surviving examples of such large scale historical pilgrimage in Western Europe (Gibbons and Walsh 2005; Harbison 1991).

\subsection{Link to Video}

The video recording is hosted on YouTube and can be accessed via this link: Video Clip

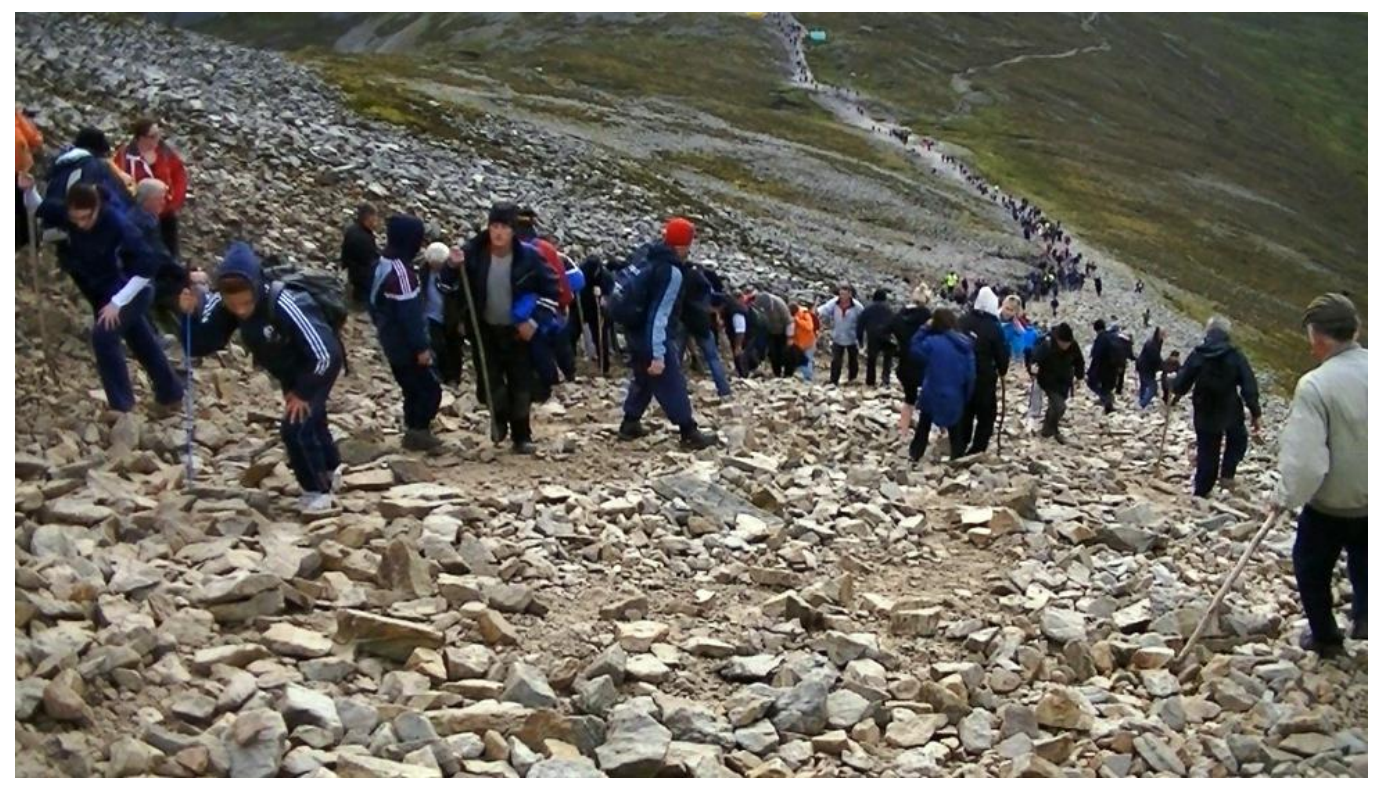

Fig. 1: 0.03 Screen shot of the scene being recorded

\subsection{Content}

\subsubsection{Description}

The video captures a section of the path, early on the main pilgrimage day. The downwards perspective gives a sense of the relatively steep incline on this stretch of the trail, the flow of people and the general landscape in which the events occur. The landscape elements in the background evoke the conical-shape of this quartzite mountain and the 
manner in which is rises out of the surrounding plain. Meanwhile, the fields of scree, intermixed with patches of greenery, demonstrate the physical forces that exert their influence on the Reek and remind us of the inclement weather that is experienced on the mountain. The route of the path is clear from both its impact on the landscape and the line of people walking. The clip shows the incline of the Casán and the loose nature of the surface.

The movement of people is the focus of the recording. The footage captures a significant flow of people, with at least forty observable individuals in the immediate area of the recording and several hundred in the background whose collective movements are discernible largely as a whole. The inner side of the path, which is distinctly eroded into the mountainside, has a continuous line of people moving along it. This flow of people extends down the Reek from the point of recording where the crowds then spread out on the more level undulating section of the path in the background. The closeness and synchronicity of the main flow makes it difficult to make out the movements of individuals, even when they are relatively close to the camcorder. The movements of small number of individuals on the outer part of the path are clearly visible. Here the descent and ascent on the looser terrain creates distinct patterns of movement.

The audio captured in the footage evokes the activity occurring around the camcorder (and researcher). A rich soundscape is presented, consisting of a combination of elements such as the movement across scree, wooden sticks tapping against rock, the numerous conversations and the wind at this height. The sense of movement and bustle is particularly effective.

\subsubsection{Movements and Moments}

While the clip provides rich and full documentation of events, a number of examples have been chosen to highlight the types of motions, interactions and encounters that are of interest in this research. A brief description of these occurrences is given, including when (in seconds) and where (far-left, left, centre, etc. and background, middleground etc.) they happen in the footage.

Ascending: The main feature of the recording is the flow of people. Given my position on a steep section of path, I was well placed to record the movements of people climbing the mountain. This is obviously an especially animated activity which offers considerable potential for study. Examples from the video, include: 0.00 left middle-ground: adolescent girl in hoody with blue walking stick, moving steadily up; 0.06 far-right middle ground: man, wearing a black hat and raincoat and using walking stick, paced ascent utilising the support of the stick; 0.11 left middleground: older man, white hair and green fleece jacket, comes into clear view from the crowd, slow and small paces, attention to footing.

Slip: Much of the surface of the path consists of loose material that can give way underfoot resulting in numerous slips and falls, particularly on Casán Phádraig. This feature, along with the steep incline in places, necessitates the use of a stave or walking stick on the journey. These slides, lurches and unbalances create noticeable corporeal movements. 0.06 centre middle-ground: man in red hat slips slightly, the stones underfoot slide downwards, movement of arms used to steady his balance; 0.10 centre middle-ground: boy (possible man's son, seems to be following him directly) also slips at that spot, momentary pause to regain balance; 0.08 right middle-ground: adolescent girl in black jacket with grey hoody (hood up) being directly followed by a younger girl in a dark blue jacket, slips backwards a little, but uses her stave to prevent falling.

Pause: As much as this is a movement filled clip, there are numerous examples of pause, even if for a brief moment, to be found. A focus on motion is not to disregard non-movement, but instead features an appreciation for its equal role. Far-left middle-ground: older man resting on a rock at side of the path, with woman standing beside him; left middle-ground (slightly below) man sitting on a rock just off the path; 0.01 right middle-ground: woman, with friend in blue jacket, taking a photo, possibly with her phone; 0.14 far-left middle-ground: man with backpack momentarily resting (moving again at 0.23 ). 


\section{Exploring the Encounters}

This video is a comprehensive documentation of the movements, and their context, which serves as the basis of an examination of the mobilities on this pilgrimage day. This then enables the study of practices based on the repeated viewing of the footage and reflection on the minor, fleeting occurrences (see Laurier and Philo 2006). The large number of people engaging in a climb or descent of a steep section of mountain contains a vast multitude of bodily movements happening every moment for an entire day. This short clip catches a glimpse of some of that liveliness and richness. It is in these captured and preserved moments that the mobilities of these people can be examined and discussed.

\subsection{Mobile People}

The geographies of mobilities are focused on the people and places of mobility, as much as the practices involved (Cresswell and Merriman 2011a). Driving, flying and walking are all enacted by mobile individuals: drivers, tourists, walkers. Mobility studies that are concerned with people begin with the corporeal: the body and its movements. It is through bodily movements that these mobilities can be observed and explored (Cresswell 2006a). The different actions described above, chosen from a large variety in the recording, can be interpreted as the movements that are the basis for the mobilities of these people.

The movements highlighted portray particular mobilities. The ascent is marked by determination, steady climbing and pauses; while the descent involves careful footing, dependency on the staves and occasional slips. These mobilities are ways of experiencing the world (Adey 2009; Cresswell 2006a). In the case of three people, whose movements are described above, it is through their movements that they are experiencing the mountain. Their movements and mobilities shape their interaction with the landscape. They are mobile people: walkers, hikers, pilgrims.

A focus on the bodily movements begins to open up an awareness of the role of unconscious or automatic rudimentary movements. The role of the non-conscious is a factor that is increasingly being explored, particularly in terms of the non-cognitive, sensuous body and pre-subjective knowing (Thrift 1996; Rose 2010). Different uses of hands in the clip is noteworthy in this regard, with a hand being the placed on a leg during a particularly large stepup to launch the other leg in a movement that the body uses itself as a fulcrum (adolescent girl at 0.06 and man on far-right at 0.21 ) or a hand reaching out to rock to use it for support (adolescent girl at 0.02, although this is just a brief touch it seems to portray an non-conscious motion). The viewing and re-viewing of the footage can, then, serve as a means of observing subtle movements that indicate non-conscious thoughts and unfolding experiences.

The moments of pause encapsulate the corporeal need for a break, to catch breath and rest muscles, and the psychological need to take stock of progress. The stop which signals a break in movement is seen as equally belonging to the performance (Crang 2004). For example, the short rest taken by the man with the backpack (0.14 far-left middle-ground) involves him looking back down the path and momentarily gathering himself before setting off again. The non-motion based activities of rest speak to mobilities as much as movements, with in-between spaces showing the results of and preparation for the walk. The case of the older man resting on a rock shows someone who needs a decent break, but also someone who despite this need is determined to carry on.

\subsection{Path}

Mobilities are seen as occurring in places and across spaces (Hannam et al. 2006; Sheller and Urry 2006). The mobile is facilitated and shaped by bridges, ports and roads. They are its context and setting (Cresswell and Merriman 2011a; Jensen 2010). The path, Casán Phádraig, is, therefore, central to the appreciation of the mobilities featured. Its incline and surface channel the mobilities of the people. In this process, the path and people are intertwined in an active, rhythm-filled, kinetic process. The mobile space of the path is animated by the combinations of the movements of people, the shuffling of stones and the soundscape. 
The challenges of climbing and descending the Casán are synonymous with Croagh Patrick. Michael Gibbons (Road to Emmaus 2011, p. 10) evokes what it is like to climb the scree: "you're walking up three feet and falling down four." The movement of thousands of people annually has led to significant erosion of the existing layers of scree. The walker's experience of the mountain is mediated by the path: it exerts the body, slows pace, requires pause, moves you along. People and their mobilities interact and respond to the path differently depending on their activity (primarily, climbing or descending) and their specific encounters (large rocks, unsecure material, other people). The changing and fluid encounters between people and the mountain show how the path channels people, but also causes instances of friction (Cresswell 2010b; Jensen 2010). By following a relatively secure route, the man wearing a black hat ( 0.06 far-right middle ground) is able to climb at steady stride, while the shifting surface of more worn part of the path requires the older man ( 0.11 left middle-ground) to be attentive to his footing. The examples of slips and lurches described show how the uncertain nature of this terrain can affect people, their movements and mobilities. The slips of the man in the red hat and the boy show how the surface can literally move beneath your foot. The body jerks and automatically responds trying to regain balance, with the stave or walking stick being utilised when available.

\subsection{Beyond}

An examination of this recording shows some of the uses of video, but equally its limits. As a tool centred on the observable, it cannot access other features, such as personal experiences, and the tactile and olfactory. Indeed, both Simpson (2011) and Spinney (2011) point out this shortcoming. While the employment of video in conjunction with other methods enables a greater understanding of events, the examination of the footage such as that featured here is still heavily dependent on personal judgements and deduction.

A substantial change in the research would assist in attempting to examine that which is beyond the reach of the video recorder, such as a video where the participants who are subjects of the video discuss it in detail. However, if this is not possible the challenge then lies in the amalgamation of fieldnotes, research diary entries, photographs, conversations and interviews to provide context and understanding for the movements and mobilities in the recording. It is, therefore, necessary to appreciate that which is beyond the realm of the video and they ways in which we can access such.

\section{Conclusion}

Discussions of video as a research methodology have highlighted the opportunities it presents the researcher and the researcher process. However, it has also been seen that video has not being utilised fully and that there are numerous issues with it as a device and integrating it with scholarship. Different geographers have been keen to experiment with video as a research method, especially in studies concerned with mobilities, practice and performance. These reflect desires to more fully engage with bodily movements and events as they are occurring in place, so as to get a sense of the fluid and unfolding nature of the world. Video offers considerable potential for the research on how people, through the use of their bodies, interact with spaces. It can capture, both aurally and visually, the complexities of everyday occurrences, corporeal movements and practices and make these passing moments available for examination. The analysis of these mobilities is greatly facilitated by the ability to view and review the recordings, while also slowing them down and pausing to study movements and moments in detail.

The descriptions and interpretations of the featured video of walkers on Croagh Patrick illustrates how video can be used in examinations of mobilities, how the material produced can be studied and how it may be presented to an audience. The study of the material reinforces the point that video captures a very large amount of data, even within this short clip. The discussions and analysis offered in this paper touch on only a few instances and specific mobilities found in this video. Simpson (2011, p, 345) notes that "the video camera recorded far more detail than would have been possible from my observations alone". Without the documenting ability of the video many encounters would have passed by being left unrecorded. The clip studied here demonstrates the range of gestures, actions and incidents that can be captured. While comprehensive field notes and a numerous photographs are essential tools in 
practice-centred research, video presents elements that they cannot. Video, then, opens up a whole sphere of flow and activity, much of which is only discovered in the reviewing and interpretation of the footage. This rich collection of material can then be used to arrive at greater understanding and meaning through the "bringing together of disparate moments and experiences" (Spinney 2011, p. 171). It is this process, in its entirety, that offers new avenues for engagements with mobilities.

A challenge remains in fully utilising video and successfully integrating it into a suite of research methods that are focused on the study of corporeal movements and mobilities. This process will involve considerations of ways to connect video and other field methods, to use recordings in analysis alongside and with materials from other research techniques and to present footage in an academic style in publications and online platforms. There is, of course, also the need for a fuller cataloguing and discussing of the usage of video within geographic research and examinations of particular aspects, such as the practicalities of recording video in the field and the incorporation of footage into publications. A critical awareness of the benefits and shortcomings in the use of video can assist in its proper employment as a central research tool. Similar to the content of the video, the use of video in research involves its own steady progress, momentary pauses for reflection and occasional slips.

Adey, P., 2010. Mobility. London: Taylor \& Francis.

Collins-Kreiner, N., 2010. Geographers and Pilgrimages: Changing Concepts in Pilgrimage Tourism Research. Tijdschrift voor economische en sociale geografie, 101(4), pp.437-448.

Crang, M., 2003. Qualitative methods: touchy, feely, look-see? Progress in Human Geography, 27(4), pp.494-504.

Crang, M., 2005. Qualitative methods (part 3): there is nothing outside the text? Progress in human geography., 29(2), pp.225-233.

Crang, M. \& Cook, I., 2007. Doing Ethnographies. London: SAGE.

Crang, P., 2004. It's Showtime: On the Workplace Geographies of Display in a Resturant in Southwest England. In A. Amin \& N. J. Thrift, eds. The Blackwell Cultural Economy Reader. Blackwell readers in geography. Malden, MA: Blackwell, pp. 307-326.

Cresswell, T., 2006a. On The Move. London: Routledge.

Cresswell, T. 2006b. 'You cannot shake that shimmie here': producing mobility on the dance floor. Cultural Geographies, 13 (1), pp. 55-77.

Cresswell, T., 2010. Towards a politics of mobility. Environment and Planning D: Society and Space, 28(1), pp.17-31.

Cresswell, T. \& Merriman, P., 2011a. Introduction: Geographies of Mobilities - Practices, Spaces, Subjects. In T.

Cresswell \& P. Merriman, eds. Geographies of Mobilities: Practices, Spaces, Subjects. Surrey, UK: Ashgate, pp. 1-19.

Davies, G. and Dwyer, C. 2007. Qualitative methods: are you enchanted or are you alienated? Progress in Human Geography, 31 (2), pp. 257-266.

D’Andrea, A., Ciolfi, L. \& Gray, B. 2011. Methodological Challenges and Innovations in Mobilities Research. Mobilities, 6(2), pp.149-160.

Delyser, D., 2010. Writing Qualitative Geography. In Dydia DeLyser et al., eds. The SAGE Handbook of Qualitative Geography. London ; Thousand Oaks, Calif: SAGE, pp. 341-358.

Foley, R. 2011. Performing Health in Place: The Holy Well as a Therapeutic Assemblage. Health \& Place, 17, pp. 470479.

Garrett, B.L., 2011. Videographic geographies: Using digital video for geographic research. Progress in Human Geography, 35(4), pp.521-541.

Geertz, C. 1973. The Interpretation of Culture. New York: Basic Books. 
Gibbons, M. and Walsh, G., 2005. Croagh Patrick, County Mayo: In the Archaology and History of Ireland, in: Croagh Patrick: Ireland's Holy Mountain. The Croagh Patrick Archaeological Committee, pp. 27-51.

Hackett, E., 2003. Clew Bay archaeological trail; sli seandalaiochta Chuan Modh: exploring 6,000 years of Mayo's heritage. South West Mayo Development Company, Mayo: Newport.

Hannam, K., Sheller, M. and Urry, J. 2006. Mobilities, immobilities and moorings. Mobilities, 1 (1), 1-22.

Harbison, P., 1994. Early Irish Pilgrim Archaeology in the Dingle Peninsula. World Archaeology, 26(1), pp.90-103.

Jensen, O.B., 2010. Negotiation in Motion: Unpacking a Geography of Mobility. Space and Culture, 13(4), pp.389402.

Latham, A. 2003. Research, performance, and doing human geography: some reflections on the diary-photograph, diary-interview method. Environment and Planning A, 35 (10), 1993-2017.

Laurier, E. and Philo, C., 2006. Cold Shoulders and Napkins Handed: Gestures of Responsibility. Transactions of the Institute of British Geographers, 31(2), pp.193-207.

Longhurst, R. 2009. Embodied Knowing: IN Thrift, N. and Kitchin, R. (eds.) International encyclopedia of human geography. Oxford: Elsevier, pp. 429-433.

Lorimer, J. 2009. Posthumanism/Posthumanistic Geographies: IN Thrift, N. and Kitchin, R. (eds.) International encyclopedia of human geography. Oxford: Elsevier, pp. 344-354.

Lorimer, J. 2010. Moving image methodologies for more-than-human geographies. Cultural Geographies, 17(2), pp. 237-258.

Luff, P. and Heath, C., 2012. Some "technical challenges" of video analysis: social actions, objects, material realities and the problems of perspective. Qualitative Research, 12(3), pp.255-279.

MacKian, S., 2010. The Art of Geographic Interpretation. In D. DeLyser et al., eds. The SAGE Handbook of Qualitative Geography. London ; Thousand Oaks, Calif: SAGE, pp. 359-372.

Morton, F. 2005. Performing ethnography: Irish traditional music sessions and new methodological spaces. Social \& Cultural Geography, 6 (5), pp. 661-616.

Nolan, M.L. 1983. Irish Pilgrimage: The Different Tradition. Annals of the Association of American Geographers, 73 (3), pp. 421-438.

Nolan, M.L., and Nolan, S. 1997, Regional Variations in Europe's Roman Catholic Pilgrimage Traditions IN: Stoddard, R.H. and Morinis, A. (eds.) Sacred Places, Sacred Spaces: The Geography of Pilgrimages. Baton Rouge: Louisiana State University, 61-93.

Road to Emmaus staff, 2011. Croagh Patrick: The glorious climb of Ireland's holy mountain. Road to Emmaus, 12(2), pp.1-45.

Rose, G., 2012. Visual Methodologies: An Introduction to Researching with Visual Materials 3rd ed., London: Sage.

Rose, M. 2010. Pilgrims: An Ethnography of Sacredness. Cultural Geographies, 17(4), pp.507-524

Rosenstein, B., 2008. Video Use in Social Science Research and Program Evaluation. International Journal of Qualitative Methods, 1(3), pp.22-43.

Saldanha, A., 2009. Photographs. In R. Kitchin \& N. Thrift, eds. International Encyclopedia of Human Geography. Oxford: Elsevier, pp. 236-240.

Sheller, M. and Urry, J. 2006. The new mobilities paradigm. Environment and Planning A, 38, pp. 207-226.

Simpson, P., 2011a. "So, as you can see ...": some reflections on the utility of video methodologies in the study of embodied practices. Area, 43(3), pp.343-352.

Sopher, D. 1967. Geography of Religions. New Jersey: Prentice-Hall. 
Spinney, J., 2011. A Chance to Catch a Breath: Using Mobile Video Ethnography in Cycling Research. Mobilities, 6(2), pp.161-182.

Thrift, N. 1996. Spatial formations. London: Sage.

Vergunst, J. 2011. Technology and Technique in a Useful Ethnography of Movement. Mobilities, 6(2), pp.203-219.

\section{Acknowledgments}

Thanks to Muireann Crowley, Sinéad O'Connor and Sarah Thelen for their helpful comments on the paper. And further to María José Rivas, for her input and assistance. Lastly, thanks to John Crowley for this in-depth engagement and support.

\section{Biographical statement}

Richard Scriven is a PhD candidate in the Geography Department UCC. His research explores pilgrimage practices in contemporary Ireland as forms of embodied mobility. The study is informed by the geographies of mobilities, nonrepresentational geographies and research on self and landscape.

\section{Contact details}

Richard Scriven, Department of Geography, University College Cork, Cork, Ireland.

102087081@umail.ucc.ie 